$$
\begin{aligned}
& \text { كزارش كو تاه علمى } \\
& \text { تأثير اندازه بذر بر مؤلفههاى جوانهزنى ذرت (Zea mays) در آزمايشگاه }
\end{aligned}
$$

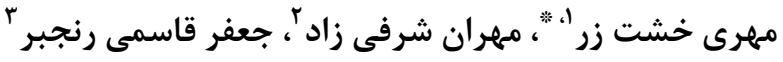

$$
\begin{aligned}
& \text { ' كارشناس مؤسسه تحقيقات ثبت و كواهى بذر و نهال واحد خوزستان }
\end{aligned}
$$

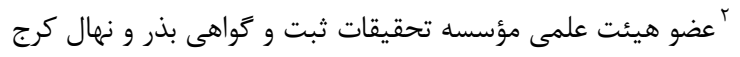

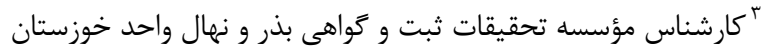

$$
\begin{aligned}
& \text { info@ spcri.ir : }
\end{aligned}
$$

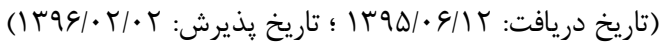

جوانهزنى و استقرار مطلوب بذر در مزرعه متأثر از شاخصهاى مختلف قدرت بذر از جمله اندازه بذر است.

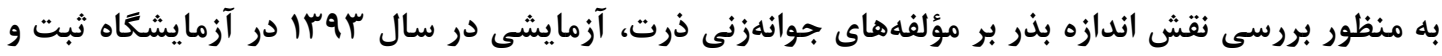

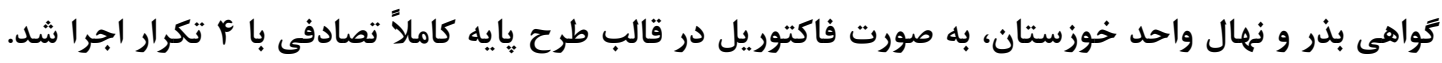

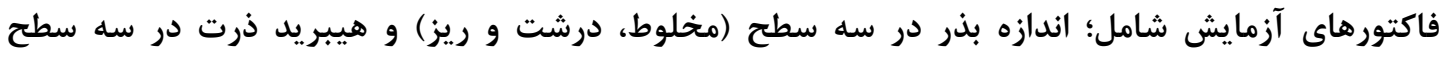

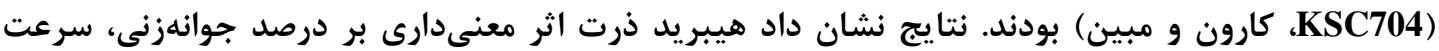
جوانهزنى، شاخص بنيه بذر، طول ريشهجه، طول ساقهجه و وزن خشك گياهجه داشت. همجنين بيشترين درصد جوانهزنى ( آ/

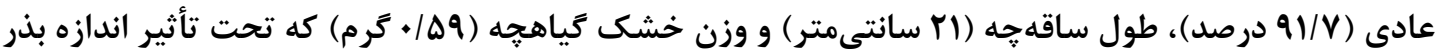

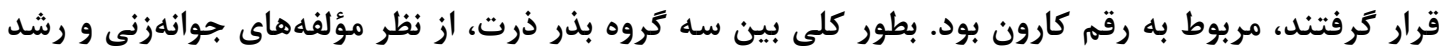

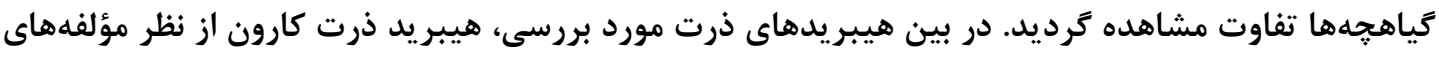
جوانهزنى بهتر از بقيه بود.

$$
\text { وازههاى كليدى: بذرهيبر يد، سرعت جوانهزنى، ذرت }
$$

جنبه هاى نوآورى: ا - استفاده از بذور درشت به جهت داشتن ذخيره دانه بيشتر سبب افزايش درصد سبزشدن كياهحهها و استقرار

$$
\text { بوتهاى بيشتر در مزرعه خواهد شد. }
$$

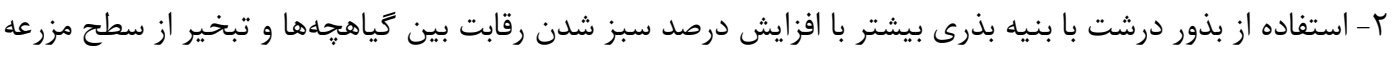

$$
\text { را كاهش مى دهد. }
$$

نظر مىرسد موفقيت در جوانهزنسى و اسـتقرار كياهجـهـ، مقدمه

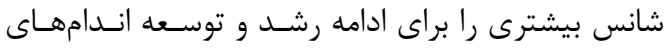

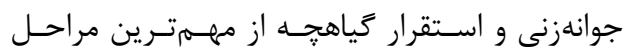

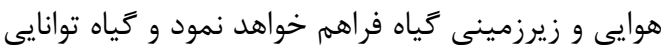

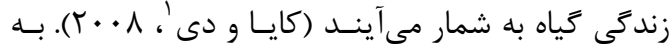

بيشترى در تحمل تنشهاى محيطى نشـان خواهـــ داد

\footnotetext{
${ }^{1}$ Kaya and Day
} 
انتخاب و سيس نمونه ثانويه به وزن تقريبى • •

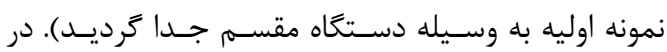

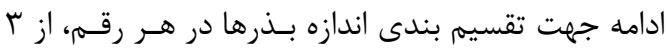
سرى الك (در اندازههاى \&، ه/9 و V ميلى متر) اسـتفاده

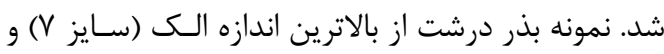

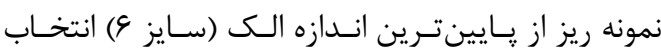

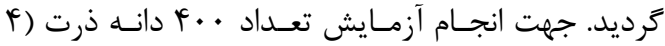

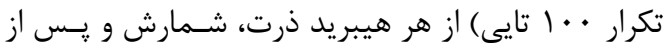
ضدعفونى درون جعبههاى يلاسـتيكى (ابعاد ها × • (T)،

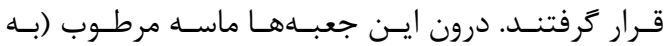

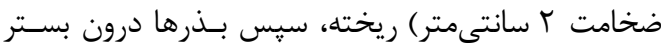
ماسه كشت شده و روى آنها نيز ماسه مرطـوب ريختهـهـ

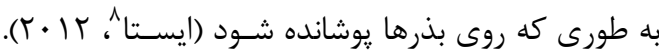

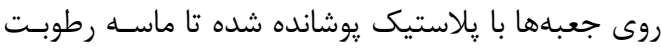
خود را از دست ندهد. مـوقعى كـهـ تمـام بـذرها كاشـته

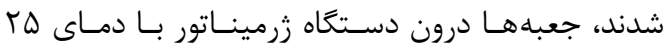

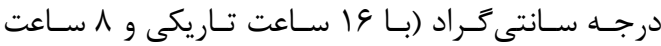
روشنايى) و رطوبت نسـبى هN درصـد قـرار داده شــند. مدت زمان كشت تـا شــارش نهـايى، هفـت شـــــانه روز

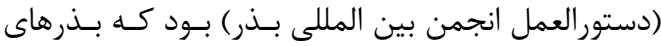

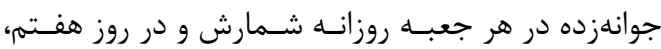
صفت درصد جوانهزنى با شـمارش تعـداد كياهجـهـهــاى عادى (به كياهجه هايى كَفته مىشـود كـهـ داراى ريشـهـ،

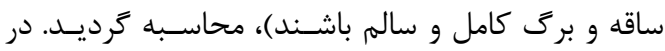

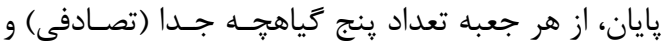

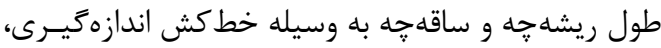
سيس جهـت وزن خشـك درون دسـتكاه آون قـرار داده

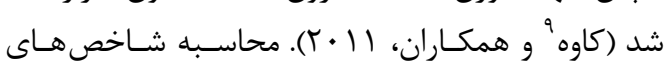
جوانهزنى با استفاده از رابطههاى زير صورت كرفت:

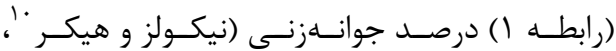

$:(199 \wedge$

$\frac{S}{T} \times 100$

در اين رابطه، S تعداد بذرهاى جوانهزده و T تعـداد كـل بذرها در واحد آزمايش مىباشد.

\footnotetext{
${ }^{8}$ ISTA (International Seed Testing Association)

${ }^{9}$ Kaveh

${ }^{10}$ Nicols and Heydecker
}

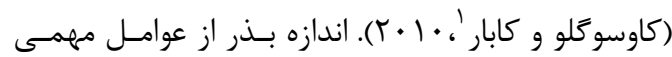
است كه بر سبزشدن يكنواخت بوتهها اثرگذار استت و از

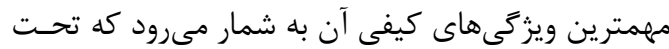

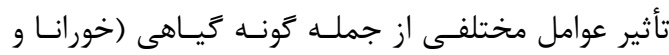

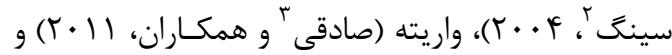

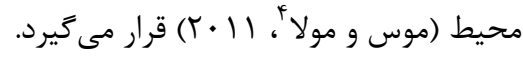

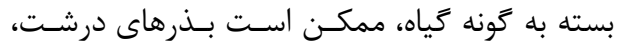
درصد جوانهزنى بيشترى نسبت به بذرهاى ريز دارا بـوده

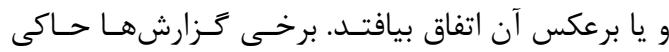
است رابطه مثبت قوى بين حجم بذر، درصد بقاء، قدرت

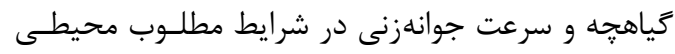

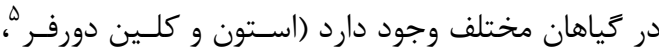

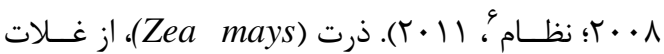
مهمم و با ارزش مناطق گرمسير و معتدل جهان است كـهـ

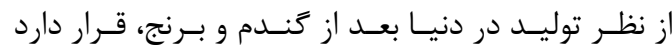

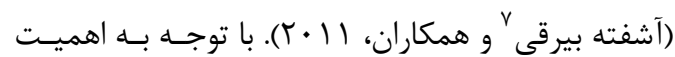
كشت ذرت در مناطق مساعد و رويكرد مثبت نسـبت بــهـ

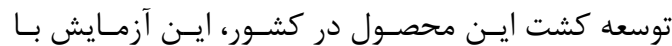

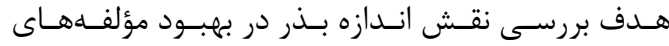
جوانهنى گياه ذرت انجام شد.

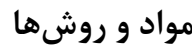

آزمايش در سال سوسا در آزمايشعاه ثبت و گواهى بذر و نهال خوزستان واقع در مركز تحقيقـات كشـاورزى

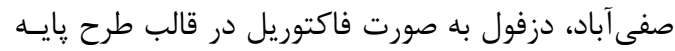
كاملاً تصادفى با ب أتكرار اجرا شد. فاكتورهـاى آزمـايش: اندازه بذر در r سطح (مخلوط، درشت و ريـز) و هيبريـد

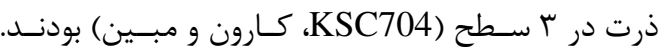

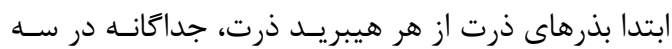
كروه مخلوط، درشت و ريز تقسيم شـدند (ابتـدا قبـل از

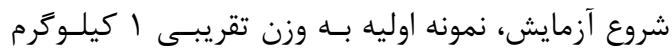

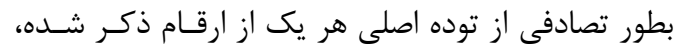

\footnotetext{
${ }^{1}$ Cavusoglu and Kabar

${ }^{2}$ Khurana and singh

${ }^{3}$ Sadeghi

${ }^{4}$ Mwase and Mvula

${ }^{5}$ Easton and Kleindorfer

${ }^{6}$ Nizam

${ }^{7}$ Ashofteh Beiragi
} 
بذر و الكَوى تخصيص منابع نيز بستگى دارد (لمبيز و و

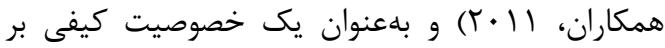

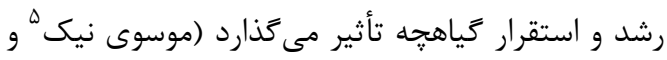

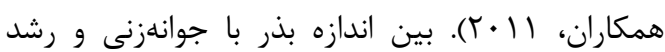

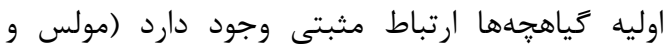

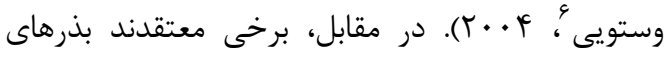

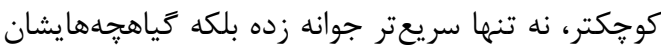

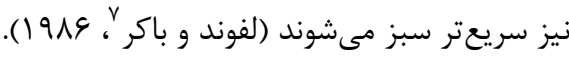

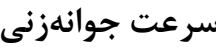

اثر هيبريد ذرت، اندازه بذر و برهمكنش آنها براى

صفت سرعت جوانهزنى در سطح احتمال يك درصد معنى دار شد (جدول ()). بذرهاى هيبريد كارون (N/F)

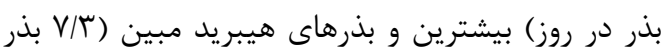

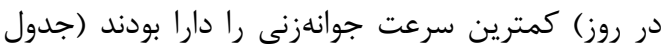

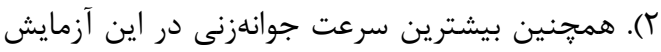

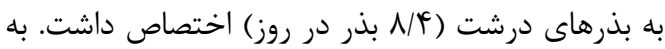

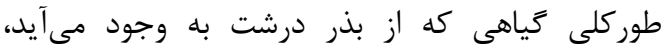
سريعتر رشد كرده و تجمع ماده خشك بيشترى داشته

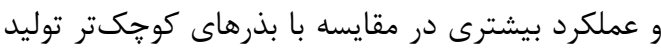

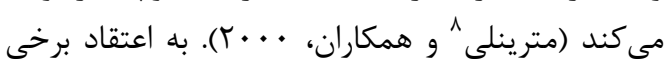
محققان تفاوت در اندازه بذر، ظهور گياهجٍه را تحت

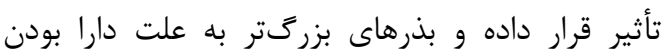
ذخيره غذايى بيشتر، از پرتانسيل جوانهزنى و سرعت بالاترى جهت سبز شدن برخوردارند (موس و مولا،

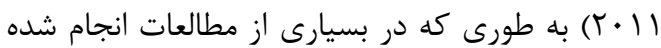

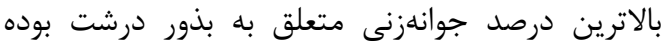

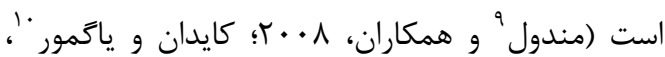

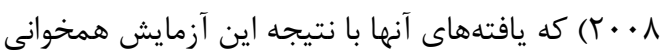

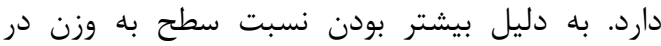
بذرهاى ريز در مقايسه با بذرهاى درشت، سرعت جذب

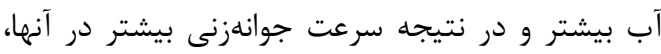

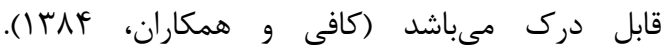

\footnotetext{
${ }^{4}$ Lembiz

${ }^{5}$ Moussavi Nik

${ }^{6}$ Moles and Westoby

${ }^{7}$ Lafond and Baker

${ }^{8}$ Matrinelli

${ }^{9}$ Mandal

${ }^{10}$ Kaydan and Yagmur
}

(رابطــه r) ســرعت جوانــززنـى (آلـيس و روبرتـزز '،

$:(191 \cdot$

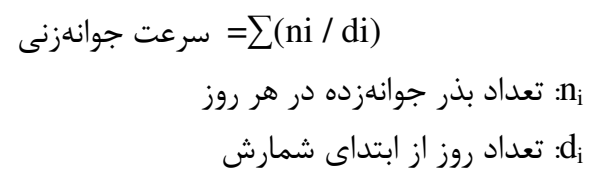

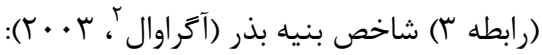

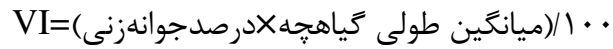
برخى از معيارهاى قابل اندازهخيرى در خلال اجراى

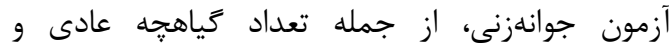

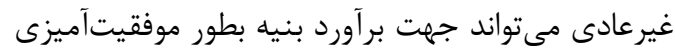

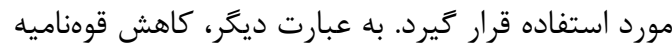
در يك توده بذر به صورت گياهجههاى غيرعادى ظهور بهر

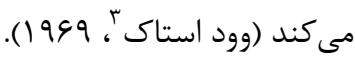

وزن خشك گیاهجه با ترازوى ديجيتالى (با دقت

$$
\text { | • • •رم) اندازهخيرى شد. }
$$

براى اندازهيرى طول ساقهجه و ريشهجه، تعداد ״نج گياهجه از هر تكرار به صورت تصادفى انتخاب و با خط كش، طول آنها اندازهخيرى و ثبت شد.

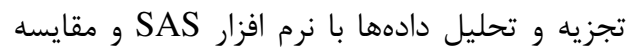

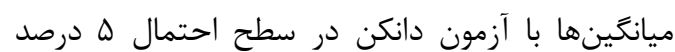

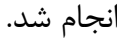

نتايج و بحث درصد جوانهزنى اثر هيبريدهاى ذرت مورد استفاده براى درصد جوانهزنى در سطح احتمال ينج درصد معنىدار شد. اثر

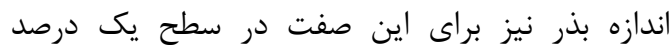
معنى دار شد ولى برهمكنش هيبريد ذرت در اندازه بذر بر بر بر اين صفت معنىدار نشد (جدول ()). هيبريد ذرت

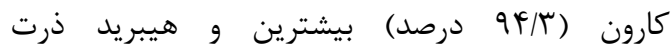

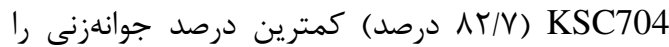
داشتند (جدول Y). همجنين از لحاظ درصد جوانهزنى، بذرهاى درشت و مخلوط با 9r/V درصد در يك سطح (a) قرار گرفتند (جدول r). جوانهزنى علاوه بر عوامل بيرونى مانند دما و نور، به مقدار منابع ذخيره شده در

\footnotetext{
${ }^{1}$ Ellis and Roberts

${ }^{2}$ Agrawal

${ }^{3}$ WoodStock
} 
خشتزر و همكاران: تأثير اندازه بذر بر مؤلفههاى جوانهزنى ذرت در آزمايشگاه...

جدول ا- تجزيه واريانس اثر هيبريد ذرت و اندازه بذر براى برخى صفات جوانهزنى بذر ذرت

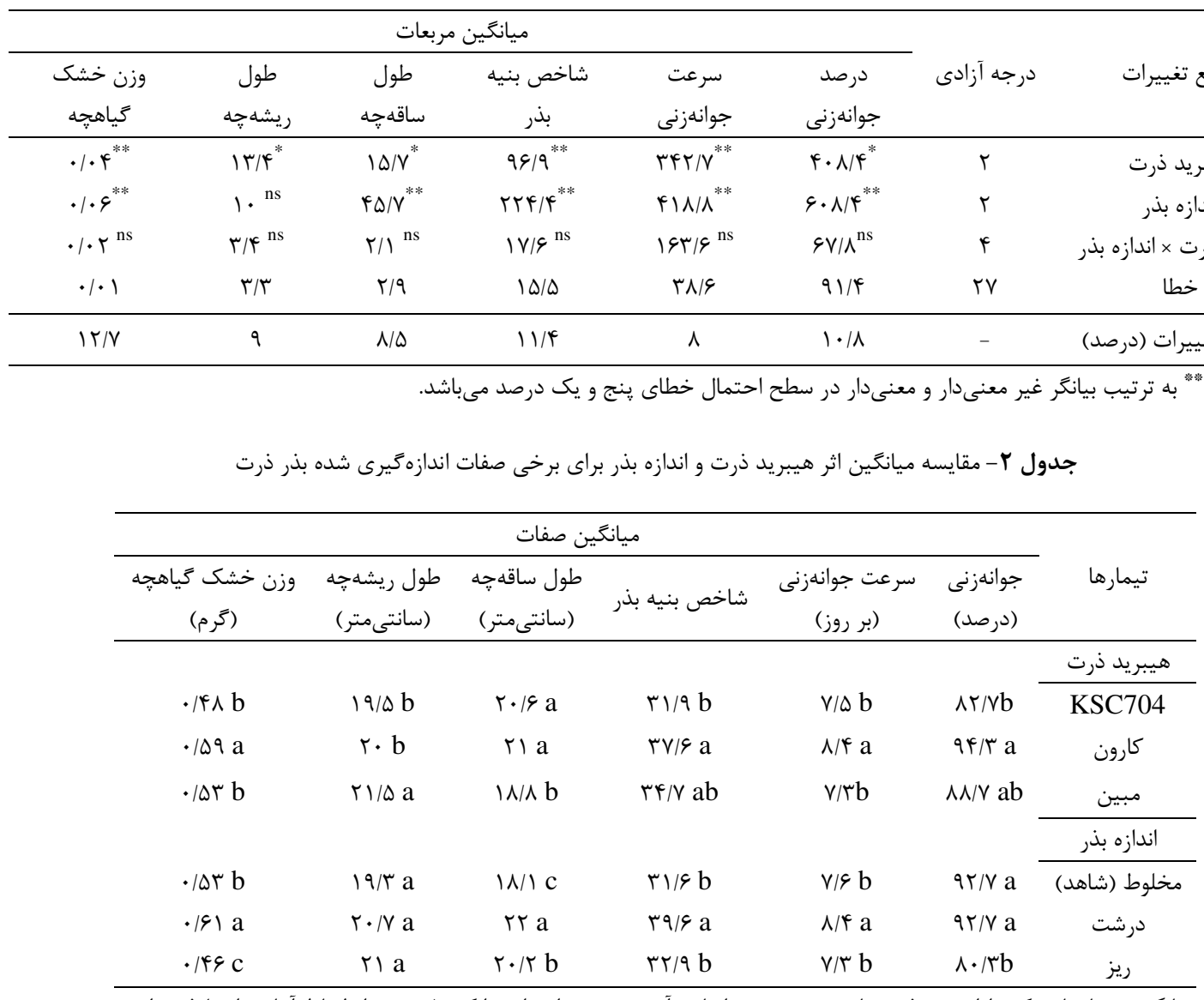

ميانگين تيمارهايى كه داراى حروف مشابهى هستند؛ بر اساس آزمون جند دامنهاى دانكن ه درصد از لحاظ آمارى اختلاف ندارند.

طول ساقه جه

اثر هيبريد ذرت براى صفت طول ساقهجه در سطح

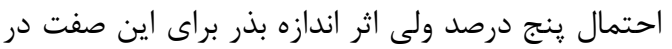

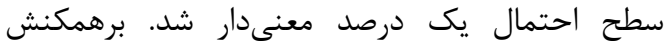

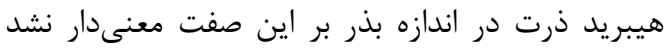

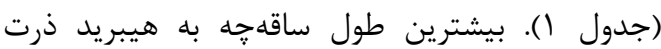
كارون (آT سانتىمتر) و اندازه درشت (r T سانتىمتر)

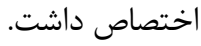
كمترين طول ساقه

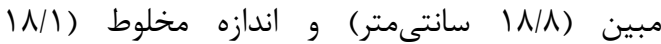
سانتىمتر) بود. طول ساقهجه از جمله صفاتى است كه بيانكر بنيه بذر است. بذرهاى با بنيه كم ممكن است

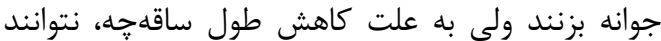

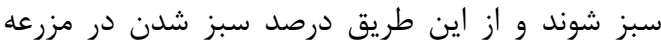
كاهش يابد. از طرفى، ساقههاى كوتاهتر به واسطه وزن درن درن
شاخص بنيه بذر

اثر هيبريد ذرت و اندازه بذر براى شاخص بنيه بذر

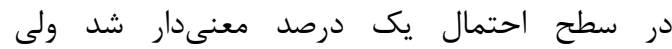
برهمكنش هيبريد ذرت در اندازه بذر براى اين صفت

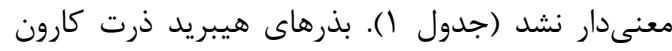

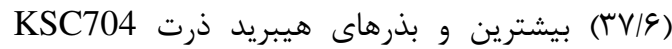

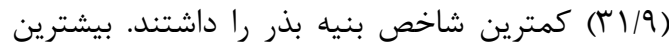

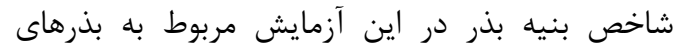

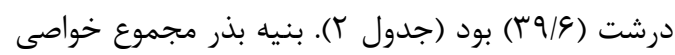
است كه درجه توان توده بذر را طى جوانهزنى و رشد كياهجه تعيين مى كند. دلايل زيادى از جمله زنوتين، اندازه، وزن و بيمارى

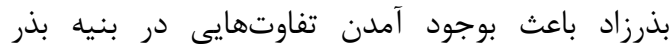

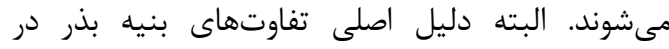

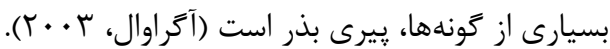


ولى به دليل داشتن سطح تماس زيادتر، كياهجههاى در

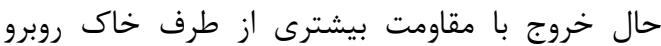

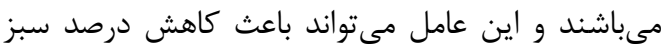

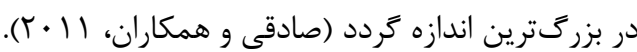

نتيجه تيرى

در اين آزمايش، اندازه بذر روى بيشتر صفات مورد ارزيابى اثر معنىدارى نشان داد. اثر اندازه بذر در صفات بات بدات مختلف رشد متفاوت و اين تفاوت در صفات اندازهخيرى شده در هيبريدهاى ذرت مورد مطالعه معنى إر بود. بر اساس نتايج به دست آمده، استفاده از بذرهاى درشت درئ ذرت مىتواند سبب بهبود استقرار كياهجه شود كه افزايش عملكرد محصول ذرت رات ران در بيى خواهد داشت شايد به دليل آنكه بذرهاى با اندازه بزركتر، سريعتر رشد كرده و يا به اين دليل كه براى مدت زمان طولانىترى رشد مى كنند، مىتوانند با استقرار كياهحه بيشتر رابطه داشته باشند. هر جند كأند كه تقسيم اثر اندازه بذر به اجزاى آن، روشهاى تحقيقاتى مناسبى را براى كند و كاو نياز دارد اما در اين رابطه مى توتوان از طول

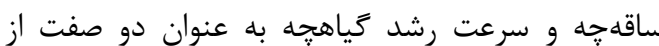
شاخصهاى قدرت بذر كه از تنوع مناسبى در ارتباط با

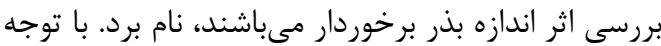

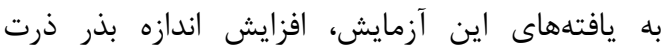

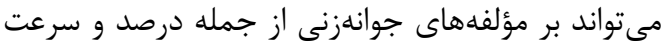

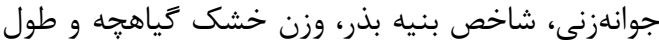
ساقهجه تأثير معنى درشت نسبت به بذرهاى ريز نتايج سودمندى در رشد

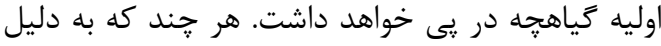
انجام آزمايش در شرايط كنترل شده آزمايشكاه، امكان

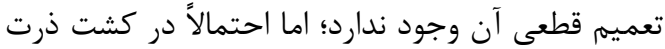
استفاده از بذرهاى درشتر، افزايش درصد و سرعت

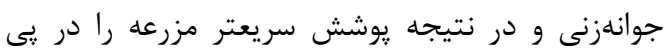

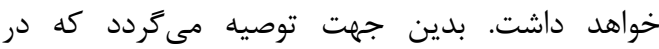
مطالعات آتى اثر اندازه بذر ذرت بر مؤلفههاى جوانهزنى و سبزشدن در شرايط مزرعهاى مورد بررسى قرار كيرد. بلهطور كلى مىتوان نتيجه كرفت كه هيبريد ذرت كارت كارون با اندازه درشت از نظر جوانهزنى و صفات وابسته بـانه به آنه

$$
\text { برترين تيمار بود. }
$$

خشك كمتر در مقايسه با ساقههاى طويلتر، داراى قدرت سبز شدن پائينترى هستند (ماتيوس و خواجه

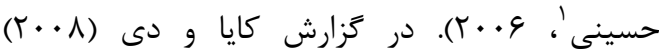
بيشترين طول ساقهجه مربوط به بذرهاى كوجكتر بود كه نسبت به بذرهاى بزركتر در اين مورد اختلاف

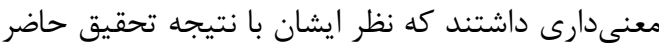

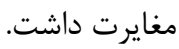

\section{طول ريشه}

اثر هيبريد ذرت بر طول ريشه

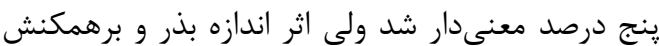
هيبريد ذرت در اندازه بذر براى اين صفت معنى دار نشد (جدول (). بيشترين طول ريشه ته مربوط به هيبريد

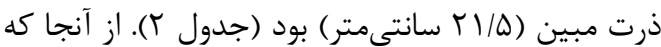
تأثير اندازه بذر بر طول ريشهجه معنى دار نبود، بنابراين كاهش وزن خشك كياهجه فقط با توجه به لاغرتر بودن باهن

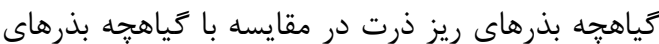
درشت قابل توجيه است.

وزن خشك تياهجه اثر هيبريد ذرت، اندازه بذر و برهمكنش هيبريد ذرت در اندازه بذر براى اين صفت در سطح يك درصد

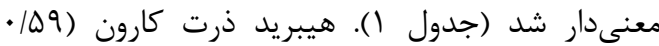

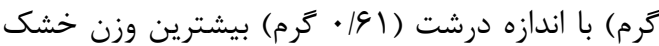
كَياهجه را دارا بود. كمترين وزن خشك كياهجهها نيز

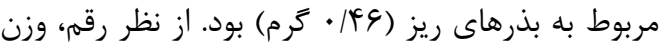

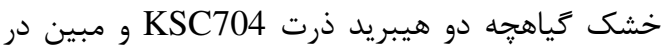

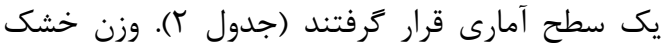
بيشتر، در هيبريد ذرت كارون مىتواند ناشى از سرعت

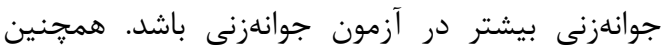

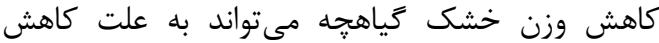
ميزان يويايى ذخاير بذر يا كاهش كارايى تبديل ذخاير يويا باشد. توليد كياهجههاى با وزن خشك بدائ بيشتر مىتواند به علت اندوخته موادغذايى بيشتر در بذرهاى باسي

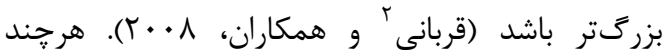
بذرهاى بزركتر توان بيشترى براى خروج از خاك دارند

\footnotetext{
${ }^{1}$ Matthews and Khajeh Hosseini

${ }^{2}$ Ghorbani
} 
Agrawal, R. 2003. Seed Technology. Public. Co. PVT. LTD. New Delhi. India.

Ashofteh Beiragi, M., Ebrahimi, M., Mostafavi, K., Golbashy, M., and Khavari Khorasani, S. 2011. Study of morphological basis of corn (Zea mays L.) yield under drought stress condition using correlation and path coefficient analysis. Journal of Cereals and Oilseeds, 2(2): 32-37.

Cavusoglu, K., and Kabar, K. 2010. Effects of hydrogen peroxide on the germination and early seedling growth of barley under $\mathrm{NaCl}$ and high temperature stresses. Eurasian Journal of BioSciences, 4: 70-79. https://doi.org/10.5053/ejobios.2010.4.0.9

Ellis, R.H., and Roberts, E.H. 1980. Towards a rational basis for testing seed quality. ProceedingsEaster School in Agricultural Science, University of Nottingham. 605-635.

Ghorbani, M.H., Soltani, A., and Amiri, S. 2008. The effect of salinity and seed size on response of wheat germination and seedling growth. Journal of Agricultural Sciences and Natural Resource, 14(6): 44-52.

ISTA. 2012. International Rules for Seed Testing. The International Seed Testing Association (ISTA) Zurich Switzerland.

Kaveh, H., Vatandoost, S., Aruee, H. and Mazhabi, M. 2011. Would Trichoderma affect seed germination and seedling quality of two Muskmelon cultivars, Khatooni and Qasri and increase their transplanting Success. Journal of Biological and Environmental Sciences, 5: 166-175.

Kaya, M.D., and Day, S. 2008. Relationship between seed size and $\mathrm{NaCl}$ on germination, seed vigor and early seedling growth of sunflower (Helianthus annuus L.). African Journal of Agricultural Research, 3(11): 787-791.

Kaydan, D., and Yagmur, M. 2008. Germination, seedling growth and relative water content of shoot in different seed sizes of triticale under osmotic stress of water and $\mathrm{NaCl}$. African Journal of Biotechnology, 7(16): 2862-2868.

Khurana, E., and Sing, J.S. 2004. Germination and seedling growth of five tree species from tropical dry forest in relation to water stress: impact of seed size. Journal of Tropical Ecology, 20(4): 385-396. https://doi.org/10.1017/S026646740400135X

Lafond, G.P., and Baker, R.G. 1986. Effects of temperature moisture stress, and seed size on germination of nine spring wheats. Crop Science, 26: 563-567. https://doi.org/10.2135/cropsci1986.0011183X002600030028x

Lembicz, M., Olejniczak, P., Żukowski, W., and Bogdanowicz, A.M. 2011. Effect of mother plant age on germination and size of seeds and seedlings in the perennial sedge Carex secalina (Cyperaceae). Flora-Morphology, Distribution, Functional Ecology of Plants, 206(2): 158163. https://doi.org/10.1016/j.flora.2010.09.006

Lyndlee, C.E. and Kleindorfer, S. 2008. Germination in two australian species of Frankenia L., F. Serpyllifolia Lindl. and F. Foliosa JM Black (Frankeniaceae)-Effects of Seed Mass, Seed Age, Light, and Temperature. Transactions of the Royal Society of South Australia, 132(1):29-39. https://doi.org/10.1080/03721426.2008.10887090

Mandal, S.M., Chakraborty, D., and Gupta, K. 2008. Seed size variations: Influence on plant growth. Research Journal of Seed Science, 1(1): 26-33.

Matrinelli-Seneme, A., Zenotto, M.D. and Nakagawa, J. 2000. Seed size and shape effect on corn seed quality, cultivar AL-34. Revista Brasilevia de Sementes, 22(1): 232-238. 
Matthews, S., and Khajeh Hosseini, M. 2006. Mean germination time as an indicator of emergence performance in soil of seed lots of maize Zea mays (L.). Seed Science and Technology, 34: 339-347. https://doi.org/10.15258/sst.2006.34.2.09

Moles, A.T., and Westoby, M. 2004. Seedling survival and seed size: A synthesis of the literature. Journal of Ecology, 92(3): 372-383. https://doi.org/10.1111/j.0022-0477.2004.00884.x

Moussavi Nik, M., Babaeian, M., and Tavassoli, A. 2011. Effect of seed size and genotype on germination characteristic and seed nutrient content of wheat. Scientific Research and Essays, 6: 2019-2025. https://doi.org/10.5897/SRE11.621

Mwase, W.F., and Mvula, T. 2011. Effect of seed size and pre-treatment methods of Bauhinia thonningii Schum. on germination and seedling growth. African Journal of Biotechnology, 10(26): 5143-5148.

Nicols, M.A., and Heydecker, W. 1968. Two approaches to the study of germination date. Proceeding of International Seed test Associated, 33(3): 531-540.

Nizam, I. 2011. Effects of salinity stress on water uptake, germination and early seedling growth of perennial ryegrass. African Journal of Biotechnology, 10(51): 10418-10424. https://doi.org/10.5897/AJB11.1243

Sadeghi, H., Khazaei, F., Sheidaei, S., and Yari, L. 2011. Effect of seed size on seed germination behavior of safflower (Carthamus tinctorius L.). Journal of Agricultural and Biological Science, 6(4): 5-8. 


\title{
The Effect of Seed Size on Maize (Zea mays) Germination Characteristics in Vitro
}

\author{
Mehri Khesht Zar ${ }^{1, *}$ Mehran Sharafizad ${ }^{2}$ Jafar Ghasemi Ranjbar ${ }^{3}$ \\ ${ }^{1}$ Expert, Seed and Plant Certification and Registration Institute, Khuzestan Branch, Khuzestan, \\ Iran \\ ${ }^{2}$ Member of the Scientific, Seed and Plant Certification and Registration Institute, Karaj \\ ${ }^{3}$ Expert, Seed and Plant Certification and Registration Institute, Khuzestan Branch, Khuzestan, \\ Iran \\ "Corresponding author, E-mail address: info@ spcri.ir
}

(Received: 02.09.2016; Accepted: 22.04.2017)

\begin{abstract}
To investigate the role of seed size on maize germination characteristics, an experiment was conducted in 2014 in the Laboratory of Registration and Certification of Seeds and Plants, Khuzestan Branch. Treatments included three levels of seed size (control (mixed), large and small) and hybrids at three levels (KSC704, Karun and Mobin). The results of these experiments showed that the hybrid had a significant impact on germination percentage, the rate of germination, vigor index, root and shoot length and dry weight of seedling. In addition, the highest germination (94.3\%), the rate of germination (8.4 seeds per day), vigor index (37.6), shoot length $(21 \mathrm{~cm})$, root fresh weight $(3.1 \mathrm{gr})$ and dry weight of seedlings $(0.59 \mathrm{~g})$ affected by seed size belonged to the Karun hybrid. Generally speaking, in terms of germination and seedling growth, there were differences among the three groups of maize seeds. Out of the hybrids scrutinized, Karun hybrid was a better one in terms of germination and growth of seedlings.
\end{abstract}

\section{Keywords: Hybrid seed, Germination rate, Maize}

\section{Highlights:}

1- Due to higher storage capacity, the use of large seeds brings about increases in the seedling germination rate and their establishment in the field.

2- The use of large seeds with more seed vigor decreases competition between seedlings and reduces vapor from the field. 